\title{
Non-Sterile Volumetric Powder Filling Method
}

National Cancer Institute

\section{Source}

National Cancer Institute. Non-Sterile Volumetric Powder Filling Method. NCI Thesaurus.

Code C112997.

A process that fills a dosage unit with a powder by volume using gravity flow, which is not performed under sterile conditions. 